\title{
Caracterização de surimi obtido a partir da carne mecanicamente separada de tilápia do Nilo e elaboração de fishburger
}

\section{Characterization of surimi from mechanically deboned tilapia meat and fishburger preparation}

\author{
Fabíola Helena dos Santos Fogaça ${ }^{1 *}$; Fabrizia Sayuri Otani²; Carolina De Gaspari \\ Portella ${ }^{3}$; Luiz Gonzaga Alves dos Santos-Filho ${ }^{4}$; Léa Silvia Sant’Ana ${ }^{5}$
}

\section{Resumo}

Este estudo teve como objetivos obter produtos (surimi e fishburger) a partir da carne mecanicamente separada (CMS) de tilápia do Nilo (Oreochromis niloticus) e avaliar seus aspectos químicos, microbiológicos, nutricionais e sensoriais. Para elaboração do fishburger, a CMS foi submetida a lavagens sucessivas, obtendo-se um concentrado protéico definido como surimi. A caracterização química da CMS e do surimi foi determinada pelas análises da composição química (umidade, proteína e lipídeos) e do perfil de aminoácidos. As análises microbiológicas foram realizadas para Estafilococos, coliformes a $45^{\circ} \mathrm{C}$ e Salmonella sp. A análise sensorial do fishburger foi realizada por meio da aplicação do teste de aceitação global, avaliando-se parâmetros como aparência, sabor, odor e textura. O surimi apresentou menores teores proteico $(14,81 \%)$ e lipídico $(7,15 \%)$ e maior umidade $(75,44 \%)$ em comparação à CMS $(\mathrm{P}<0,05)$. Os perfis de aminoácidos da CMS e do surimi foram semelhantes, apresentando alto valor nutricional pela sua composição de aminoácidos essenciais. A análise microbiológica demonstrou que o produto estava dentro do padrão sanitário exigido pela legislação. A análise sensorial obteve notas próximas de 7,0 para aparência, sabor, odor, textura e aceitação geral. Com base nos resultados obtidos, conclui-se que o surimi pode ser utilizado na elaboração do fishburger por apresentar atributos sensoriais, nutricionais e microbiológicos desejáveis e por estimular o aproveitamento dos coprodutos gerados na filetagem da tilápia.

Palavras-chave: Aminoácidos, aceitação global, atributos de qualidade, CMS

\begin{abstract}
The aim of this study was to obtain products (surimi and fishburger) from mechanically separated meat (MSM) of Nile tilapia (Oreochromis niloticus), and evaluate its aspects chemical, microbiological, nutritional and sensory attributes. For fishburger preparation the MSM was submitted to successive washes cycles, to obtaining a protein concentrate defined as surimi. The composition of MSM and surimi was determined by analysis of moisture, protein, lipid and amino acid profile. Microbiological analysis were performed for Staphylococcus sp., coliforms at $45^{\circ} \mathrm{C}$ and Salmonella sp. Sensory analysis of fishburger was performed by the global acceptance testing, for evaluation of parameters such as general appearance, odor, flavor and texture. The surimi showed lower protein $(14.81 \%)$ and lipid $(7.15 \%)$ content and higher moisture $(75.44 \%)$ compared to the MSM $(\mathrm{P}<0.05)$. The amino acid

\footnotetext{
1 Pesquisadora, Empresa Brasileira de Pesquisa Agropecuária, Embrapa, Parnaíba, PI. E-mail: fabiolafogaca@yahoo.com.br

2 Prof ${ }^{a}$, Universidade Federal do Oeste do Pará, UFOPA, Santarém, PA. E-mail: fabrizia_otani@yahoo.com.br

3 Discente, Centro de Aquicultura da Universidade Estadual Paulista, UNESP, CAUNESP, Jaboticabal, SP. E-mail: portella@ gmail.com

4 Técnico, Universidade Federal do Piauí, UFPI, Parnaíba, PI. E-mail: luizgonga@hotmail.com

5 Prof ${ }^{a}$, Centro de Aquicultura da UNESP, CAUNESP, Jaboticabal, SP. E-mail: santana@fca.unesp.br

* Autor para correspondência
} 
profile of MSM and surimi was similar, with high nutritional value caused by its essential amino acids presence. Microbiological analysis showed that the product was according with the sanitary standard required. Sensorial analysis determined notes near to 7.0 for appearance, flavor, odor, texture and overall acceptability. Based on these results, it is concluded that the surimi can be used in the preparation of fishburger by presenting desirable attributes for sensory, nutritional and microbiological parameters, and encourage the use of co-products generated in the tilapia filleting industry.

Key words: Amino acids, global test, quality attributes, minced

\section{Introdução}

A popularização do consumo do pescado é uma das barreiras a serem vencidas para a expansão da aquicultura no país (BORGHETTI; OSTRENSKY, 1999), pois a média de consumo per capita de 9,0 $\mathrm{kg}$ de peixe/ano no Brasil (MPA, 2010a) ainda está abaixo do recomendado pela Organização Mundial da Saúde - OMS (12,0 kg/hab./ano). O pescado é um alimento de alto valor nutricional, fácil digestão, fonte de minerais e vitaminas (OGAWA; MAIA, 1999) e quando industrializado pode atender às necessidades do consumidor nos aspectos sensoriais (sabores agradáveis, suaves e característicos), conveniência (fácil preparo) e econômico (com preços acessíveis) (FERREIRA et al., 2002).

Para atender à demanda por produtos préprontos, as indústrias processadoras passaram a comercializar filés de pescado no mercado interno, gerando quantidade relevante de coprodutos e resíduos. No intuito de diminuir custos e agregar valor aos produtos gerados, as beneficiadoras estão buscando maneiras de aproveitamento desses subprodutos (PESSATTI, 2001), como fazem as indústrias de carne bovina e de frango. Esse aproveitamento reduz custos e é uma forma de evitar danos ao meio ambiente pela disposição inadequada desse material (SUCASAS, 2011). No entanto o aproveitamento de resíduos no ciclo de produção de pescado ainda é pouco significativo na indústria brasileira (BRITO, 2007). Estima-se que frigoríficos processadores de peixe desperdiçam entre $62,5 \%$ e $66,5 \%$ (BOSCOLO; HAYASHI; MEURER, 2004) e de camarão aproximadamente $50 \%$ da matéria-prima (LIMA et al., 2007).

Um dos coprodutos gerados pela indústria de processamento da tilápia é a carne mecanicamente separada ou CMS, obtida pela extração mecânica da carne aderida à espinha dorsal após a filetagem (KIRSCHNIK; MACEDO-VIEGAS, 2009). No entanto a CMS in natura apresenta alto teor de lipídeo e substâncias indesejáveis (pigmentos, sangue, etc.) que aceleram sua degradação, conferindo ao produto sabor e odor indesejáveis (TENUTA-FILHO; JESUS, 2003).

O surimi consiste em uma base protéica, obtida a partir do músculo de pescado, submetida a lavagens sucessivas (em que se eliminam gordura, sangue, substâncias odoríferas e proteínas solúveis em água), refino, desidratação, adição de crioprotetores e congelamento para sua preservação (LEE, 1984). A tecnologia de processamento do surimi é uma maneira de agregar valor à CMS do processamento de peixes, aumentando sua vida útil e oferecendo à indústria maior flexibilidade na elaboração de produtos. Por apresentar características como ausência de odor de peixe, alto teor protéico e baixo teor de lipídeo, o surimi pode ser acrescentado a todos os tipos de alimento como sopas, hambúrguer, embutidos, entre outros (ALFARO et al., 2004).

Estudos prévios avaliando a estabilidade e qualidade da CMS de tilápia, in natura e após lavagens sucessivas, foram realizados por Gryschek, Oetterer e Gallo (2003) e Kirschnik (2007). Os resultados foram promissores e os produtos desenvolvidos (salsicha, nuggets, fishburger e bolinhos de peixe) obtiveram boa aceitação em testes de consumidores (SARY et al., 2009). Porém é necessário realizar estudos para o estabelecimento de padrões de identidade e qualidade do surimi de espécies tropicais e suas possíveis aplicações na indústria de alimentos. 
O estudo teve como objetivos aproveitar a carne mecanicamente separada (CMS) de tilápias do Nilo para obtenção de surimi utilizado na elaboração de fishburger e, ainda, avaliar os aspectos químicos, microbiológicos e nutricionais do surimi e sensoriais do fishburger elaborado.

\section{Material e Métodos}

\section{Obtenção da CMS de tilápia do Nilo}

Foram utilizados resíduos da filetagem de tilápia nilótica, obtidos do Frigorífico Fish Fácil, no município de Garça, SP. A carne foi retirada das carcaças de peixes produzidos e abatidos no local, pertencentes a um mesmo lote de produção. Os peixes, depurados por 24 horas, foram abatidos por choque térmico (com uso de água e gelo, na proporção de 1:1), eviscerados e descabeçados para retirada dos filés. Após filetadas, as carcaças dos peixes passaram por uma máquina desossadora/ despolpadora (High Tech, modelo HT 250) para a retirada do músculo aderido ao espinhaço, obtendose um produto denominado Carne Mecanicamente Separada (CMS). A CMS foi embalada em sacos de polietileno com capacidade para $2,0 \mathrm{~kg}$, congelada em túnel de congelamento $\mathrm{a}-25^{\circ} \mathrm{C}$ e posteriormente mantida em freezer a $-18{ }^{\circ} \mathrm{C}$.

A amostra foi transportada de Garça a Botucatu (aproximadamente $200 \mathrm{~km}$ ) em caixas térmicas, permanecendo congeladas. Ao chegar ao laboratório, foi mantida em freezer durante 48 horas.

\section{Processo de obtenção do surimi}

O surimi foi obtido por processamento manual. A $\mathrm{CMS}$ foi descongelada sobrefrigeração a $5^{\circ} \mathrm{C}$ durante 24 horas. Depois de descongelada, foi submetida a três lavagens sucessivas, com água destilada fria (5 $\left.{ }^{\circ} \mathrm{C}\right)$. O volume de água utilizado foi quatro vezes o peso da massa (v/v 1:4). A temperatura da água durante a lavagem foi mantida em torno dos $5{ }^{\circ} \mathrm{C}$ com o uso de gelo moído. Após cada lavagem, que durou em média 1 minuto, a amostra foi prensada manualmente em tecido de algodão. Ao final do processamento, foram adicionados crioprotetores: $2 \%$ de cloreto de sódio e $1 \%$ de sacarose. Após essa etapa, o surimi foi embalado em sacos de polietileno de $2,0 \mathrm{~kg}$ e mantido congelado $\left(-18^{\circ} \mathrm{C}\right)$ até o momento das análises.

\section{Caracterização química da CMS e do surimi}

A composição centesimal das amostras da CMS e do surimi foi realizada segundo a AOAC (2005) e as análises realizadas em triplicata. Todas as amostras foram armazenadas a $-18{ }^{\circ} \mathrm{C}$ e descongeladas a 5 ${ }^{\circ} \mathrm{C}$ por um período de 24 horas antes das análises. A umidade foi definida por secagem em estufa a $105{ }^{\circ} \mathrm{C}$ por 24 horas (método 950.46); a proteína bruta, pelo método semimicro Kjeldahl ( $\mathrm{N}$ x 6.25) (método 928.08); os lipídeos foram determinados por extração com clorofórmio metanol, segundo método de Folch, Lees e Sloane-Stanley (1957).

A oxidação lipídica foi avaliada pela formação de substâncias reativas ao ácido tiobarbitúrico (SRATB), segundo método de Vyncke (1970). As proteínas solúveis foram determinadas segundo a mensuração do nitrogênio solúvel em ácido tricloroacético (TCA), feita em avaliação do filtrado de solução TCA, conforme descrito por Stefansson et al. (2000).

Os aminoácidos foram determinados em autoanalisador por cromatografia de troca iônica, segundo Spackman, Stein e Moore (1958). As amostras foram previamente desengorduradas e hidrolisadas em $\mathrm{HCl}$; metionina e cisteína foram determinados como sulfato de metionina e ácido cistéico, respectivamente, após extração em ácido perfórmico (MOORE, 1963).

\section{Processo de elaboração do fishburger de surimi}

O fishburger de surimi foi elaborado segundo a seguinte formulação: $96,9 \%$ de surimi, $2 \%$ de sal, $1 \%$ de açúcar, $0,1 \%$ de cebola e alho desidratados. Todos os ingredientes foram misturados ao surimi 
manualmente durante 10 minutos. Depois de homogeneizada, essa mistura foi enformada em tubos de PVC de 4,0 polegadas (revestidos com uma bolsa de polietileno) e congelada a $-18^{\circ} \mathrm{C}$ por 24 horas. A massa desenformada foi fatiada com o auxílio de uma serra-fita em rodelas de 1,0 cm de espessura aproximadamente.

\section{Análises microbiológicas}

Foram realizadas análises microbiológicas dos fishburgers para a verificação da presença de Salmonella sp., estafilococos coagulase positiva e contagem de coliformes a $45^{\circ} \mathrm{C}$ pelo Serviço de Orientação à Alimentação Pública (SOAP), da Faculdade de Medicina Veterinária e Zootecnia, UNESP, Câmpus de Botucatu. Os critérios microbiológicos exigidos pela legislação para produtos à base de pescado, cozidos, em uma amostra indicativa, foram: ausência de Salmonella sp. em $25 \mathrm{~g}$ do alimento; coliformes a $45^{\circ} \mathrm{C}$ em níveis de até $10^{2} \mathrm{~g}^{-1}$; estafilococos coagulase positiva em níveis de até $5 \times 10^{2} \mathrm{~g}^{-1}$ (ANVISA, 2001). Por estarem dentro dos padrões microbiológicos exigidos pela legislação brasileira, os fishburgers foram submetidos à análise sensorial.

\section{Caracterização sensorial}

Utilizou-se o teste de aceitação global, no qual o provador deveria expressar por meio de uma escala hedônica estruturada de nove pontos o grau de gostar ou desgostar das amostras $(9=$ "gostei muitíssimo" a 1 = "desgostei muitíssimo") para avaliar a aceitabilidade dos parâmetros sensoriais de aspecto geral, aparência, sabor, odor e textura do fishburger (STONE; SIDEL, 1992). Participaram do teste 50 provadores não treinados, recrutados aleatoriamente. Os provadores receberam amostras de fishburgers $(8,0 \mathrm{~cm}$ de diâmetro x $0,5 \mathrm{~cm}$ de espessura) acondicionadas em recipientes plásticos descartáveis (pratos) codificados, submetidas ao aquecimento em grill por 3 minutos.

\section{Análises estatísticas}

Os dados obtidos foram analisados pelo programa estatístico SAS, versão 6.12, e as médias foram comparadas pelo teste de Tukey - Kramer, a 5\% de probabilidade para verificar diferenças significativas entre os tratamentos. Os resultados da análise sensorial foram avaliados pelo gráfico de frequência das respostas.

\section{Resultados e Discussão}

Os teores de umidade, proteínas e lipídeos da CMS e do surimi estão apresentados na Tabela 1. Houve diferença $(P<0,05)$ entre a CMS e o surimi para todos os parâmetros avaliados, mostrando que a lavagem da matéria-prima alterou a composição da CMS, reduzindo os teores de proteínas e lipídeos em $7,0 \%$ e aumentando a umidade em $2,0 \%$.

Tabela 1. Teores de umidade, proteína e lipídeo da CMS e do surimi de tilápia nilótica (Oreochromis niloticus).

\begin{tabular}{cccc}
\hline & Umidade (\%) & Proteína (\%) & Lipídeo (\%) \\
\hline CMS & $73,87(0,15)^{\mathrm{b}}$ & $15,87(0,33)^{\mathrm{a}}$ & $7,62(0,53)^{\mathrm{a}}$ \\
Surimi & $75,44(0,97)^{\mathrm{a}}$ & $14,81(0,59)^{\mathrm{b}}$ & $7,15(0,15)^{\mathrm{b}}$ \\
\hline
\end{tabular}

Média (desvio-padrão), $\mathrm{n}=4$. Letras minúsculas nas colunas demonstram diferença significativa entre os tratamentos $(\mathrm{P}<0,05)$.

Fonte: Elaboração dos autores. 
O aumento da porcentagem de umidade da CMS após a lavagem foi observado por outros autores (KIRSCHNIK; MACEDO-VIEGAS, 2009; MELO et al., 2011). Durante a lavagem, há uma concentração das proteínas miofibrilares como consequência da remoção das proteínas hidrossolúveis (sarcoplasmáticas) que possuem maior capacidade de hidratação (SUZUKI, 1987).

A determinação da umidade também é uma forma de avaliar a qualidade do surimi ou CMS lavada, que, no caso do produto japonês, elaborado com o Alaska pollock (Theragra chalcogramma), está diferenciado em quatro categorias: S (superclasse), com umidade entre $76,1 \%$ e $79,0 \%$; classe A, entre $79,1 \%$ e $80,0 \%$; classe $\mathrm{B}$, entre $80,1 \%$ e $81,5 \%$; classe C, quando for superior a $81,5 \%$ (MIRA; LANFER-MARQUEZ, 2005). O surimi de tilápia é considerado de excelente padrão, o que pode ser comprovado com o teor de umidade apresentado na Tabela $1(75,44 \%)$.

A porcentagem de proteína encontrada no surimi $(14,81 \%)$ foi próxima à quantidade de proteína encontrada na CMS $(15,87 \%)$. Teores de $17,48 \%$ a $15,13 \%$ foram descritos para CMS de tilápia (REBOUÇAS et al., 2012; KIRSCHNIK; MACEDO-VIEGAS, 2009) e o decréscimo do conteúdo proteico, em torno de $12,0 \%$ a $17,0 \%$, foi observado após a lavagem do peixe (VAZ, 2005). $\mathrm{O}$ teor apresentado caracteriza o surimi de tilápia como excelente fonte proteica e demonstram sua viabilidade para uso em produtos alimentícios proteicos de alto valor biológico (REBOUÇAS et al., 2012).

O surimi apresentou elevado teor de lipídeos $(7,15 \%)$ (Tabela 1) mesmo após sucessivas lavagens da CMS. Métodos convencionais de obtenção do surimi compreendem apenas três ciclos de lavagem da CMS (MINOZZO; VAZ, 2007) para eliminar até $50 \%$ da gordura da matéria-prima. No entanto os três ciclos utilizados não foram suficientes para reduzir em grandes proporções a gordura da CMS. Melo et al. (2011) e Kirschnik e Macedo-Viegas (2009), entretanto, reduziram o teor lipídico da CMS de tilápia em 17\% após um ciclo de lavagem. Baixo teor de lipídeos $(3,4 \%)$ foi encontrado em CMS obtida a partir de peixes inteiros ou aparas de filés de tilápia, o chamado corte em "V" (VIDOTTI; GONÇALVES, 2006). Kirschnik (2007) determinou teores de lipídeos de 1,85\% para CMS obtida de tilápias inteiras e de $11,97 \%$ para CMS de carcaças de tilápia devido à presença da musculatura ventral, que contém maior teor de gordura (em torno de 15\%) (REBOUÇAS et al., 2008).

Os resultados das análises de oxidação lipídica realizadas para avaliar se a presença do elevado teor lipídico influenciou a qualidade dos produtos (surimi e fishburger) indicaram baixa oxidação, expressa em substâncias reativas ao ácido tiobarbitúrico (SRATB) (Tabela 2).

Tabela 2. Características físico-químicas da CMS e do surimi de tilápia nilótica (Oreochromis niloticus).

\begin{tabular}{ccc}
\hline & SRATB $\left(\mathrm{mg} \mathrm{MDA} \mathrm{kg}^{-1}\right)$ & Nitrogênio solúvel (\%) \\
\hline CMS & $1,03(0,01)^{\mathrm{a}}$ & $10,50(0,14)^{\mathrm{a}}$ \\
Surimi & $0,83(0,02)^{\mathrm{b}}$ & $1,28(0,10)^{\mathrm{b}}$ \\
\hline
\end{tabular}

Média (desvio-padrão), $n=4$. Médias seguidas de letras diferentes nas colunas demonstram diferença significativa entre os tratamentos $(\mathrm{P}<0,05)$. SRATB = oxidação lipídica.

Fonte: Elaboração dos autores. 
Os valores de SRATB são utilizados como indicadores do grau de oxidação lipídica, quantificados em miligramas de malonaldeído (MDA), que é a principal substância formada durante a oxidação e que reage com o ácido tiobarbitúrico (VYNCKE, 1970). Os valores de SRATB demonstraram que a lavagem diminuiu em 20\% a taxa de oxidação lipídica (Tabela 2). A lavagem da CMS remove produtos primários e secundários da oxidação lipídica (EYMARD et al., 2005), prevenindo-a. Gryschek, Oetterer e Gallo (2003) e Kirschnik e Macedo-Viegas (2009) estudaram o efeito do processo de lavagem da CMS de tilápia na oxidação lipídica e também observaram menores valores de SRATB na CMS lavada em relação à CMS in natura. Segundo Ke, Cervantes e Roble-Martinez (1984) e Ogawa e Maia (1999), valores acima de $1,51 \mathrm{mg}$ de $\mathrm{MDA} \mathrm{kg}^{-1}$ pescado são classificados como inaceitáveis e podem vir acompanhados de odor e sabor característicos de ranço. Esse odor acentuado foi observado em CMS de tilápia que apresentou teores de $2,27 \mathrm{mg}$ de MDA kg-1 de CMS, provocando rejeição na análise sensorial do produto (REBOUÇAS et al., 2012). Com base nesses parâmetros, o surimi e a CMS de tilápia apresentaram níveis ótimos de MDA.
A análise da porcentagem de nitrogênio solúvel (NNP) está relacionada com a degradação protéica proporcionada pelas enzimas endógenas do músculo do peixe e por enzimas bacterianas (CONTRERASGUZMÁN, 2002). Valores oito vezes maiores de NNP foram determinados na CMS em comparação ao surimi (Tabela 2). Esses resultados demonstram que a lavagem inibe a degradação protéica da CMS pela lixiviação de compostos nitrogenados solúveis (HASSAN; MATHEW, 1999), melhorando a estabilidade do produto.

Os baixos teores de NNP corroboram os resultados da análise microbiológica (Tabela 3 ), que apresentou baixa contagem de bactérias. A ausência de estafilococos coagulase positiva e Salmonella sp. comprova que a manipulação da CMS e a elaboração do fishburger foram conduzidas dentro de padrões higiênico-sanitários adequados (SIMÕES et al., 2007). A mesma qualidade microbiológica foi observada em bolinhos de peixe (SARY et al., 2009) e fishburger de tilápia (MARENGONI et al., 2009).

Os perfis de aminoácidos da CMS e do surimi de tilápia estão demonstrados na Tabela 4. Os valores determinados nos dois produtos foram muito próximos, indicando que a lavagem não influenciou a composição aminoacídica do músculo do peixe.

Tabela 3. Características microbiológicas da CMS e do surimi de tilápia nilótica (Oreochromis niloticus).

\begin{tabular}{lccc}
\hline & Salmonella sp. & Estafilococos coagulase positiva & Coliformes a 45 ${ }^{\mathbf{C}} \mathbf{C}$ \\
\hline CMS & Ausência & $<1,0 \times 10 \mathrm{UFC} \mathrm{g}^{-1}$ & $<1,0 \times 10 \mathrm{UFC} \mathrm{g}^{-1}$ \\
Surimi & Ausência & $<1,0 \times 10 \mathrm{UFC} \mathrm{g}^{-1}$ & $<1,0 \times 10 \mathrm{UFC} \mathrm{g}^{-1}$ \\
\hline
\end{tabular}

$\mathrm{UFC}=$ Unidades formadoras de colônias.

Fonte: Elaboração dos autores. 
Tabela 4. Perfil de aminoácidos da CMS e do surimi de tilápia nilótica (Oreochromis niloticus) ( $\mathrm{g}_{100 \mathrm{~g}^{-1}}$ ).

\begin{tabular}{cccc}
\hline Aminoácido (\%) & CMS & Surimi & FAO/WHO \\
\hline Alanina & 1,08 & 1,12 & - \\
Arginina & 1,29 & 1,42 & - \\
Ácido aspártico & 1,71 & 1,74 & - \\
Glicina & 1,13 & 1,12 & $2,8-1,3$ \\
Isoleucina & 0,37 & 0,41 & $6,6-1,9$ \\
Leucina & 1,00 & 1,09 & - \\
Ácido Glutâmico & 2,56 & 2,77 & $5,8-1,6$ \\
Lisina (a.a.) & 1,86 & 1,94 & - \\
Cistina & Não detectado & 0,20 & $2,5-1,7$ \\
Metionina & 0,27 & 0,24 & $6,3-1,9$ \\
Fenilalanina & 0,74 & 0,76 & - \\
Tirosina & 0,56 & 0,61 & $3,4-0,9$ \\
Treonina & 0,78 & 0,82 & $1,1-0,5$ \\
Triptofano & 0,77 & 0,78 & - \\
Prolina & 0,83 & 0,92 & $3,5-1,3$ \\
Valina & 0,77 & 0,84 & $1,9-1,6$ \\
Histidina & 0,38 & 0,36 & - \\
Serina & 0,72 & 0,75 & \\
\hline
\end{tabular}

${ }^{1}$ Recomendações de aminoácidos essenciais a crianças de 2 a 8 anos (FAO/WHO/UNU).

Fonte: Elaboração dos autores.

Mendes (2001) também observou que a lavagem da CMS não alterou a composição de aminoácidos em comparação ao peixe fresco, para as espécies sardinha e carapau. Em estudos anteriores, o mesmo autor descreve uma leve diminuição da porcentagem de histidina na CMS de sardinha, sugerindo que esse aminoácido estava presente principalmente na sua forma livre e por isso seria de fácil lixiviação durante o processo de lavagem (MENDES; GONÇALVES; NUNES, 1991).

Os valores determinados no surimi ficaram abaixo dos descritos para outras espécies de peixes. Mira e Lanfer-Marquez (2005) encontraram valores 10 vezes maiores para lisina e ácido aspártico, 15 vezes para leucina, 5 vezes maiores para treonina, serina, alanina, fenilalanina e arginina em surimi de espécies marinhas, enquanto Kirschnik (2007) determinou valores maiores para isoleucina $(2,93)$, histidina $(1,53)$ e valina $(2,95)$. Porém os aminoácidos foram determinados em nuggets de CMS lavada de tilápia, que continham, além da carne, proteína isolada de soja, amido de mandioca e condimentos que influenciaram diretamente a composição original da matéria-prima.

Comparando-se o perfil de aminoácidos do surimi com a recomendação da $\mathrm{FAO} / \mathrm{WHO} / \mathrm{UNU}$ (1985; 1991), considera-se que o surimi atende em apenas $14,64 \%$ de isoleucina, $24,12 \%$ de isoleucina, $15,15 \%$ de leucina e $9,6 \%$ de metionina às exigências diárias para crianças de 2-5 anos (FAO/WHO/ UNU, 1985). Para crianças de 3-8 anos, o surimi atende em $100 \%$ às necessidades diárias de lisina e triptofano, em $31,54 \%$ de isoleucina, $52,63 \%$ de leucina, $14,12 \%$ de metionina, $91 \%$ de treonina, $64,61 \%$ de valina e $22,5 \%$ de histidina (FAO/WHO/ UNU, 1985; 1991), sendo considerado um produto de alto valor biológico.

No Brasil, existe um programa financiado pelo governo federal para inclusão do pescado na merenda escolar, utilizando-se a CMS de peixes (MPA, 2010b), baseado em resultados de trabalhos recentes que comprovaram boa aceitação $(>77,0 \%)$ de produtos como quibe, salsicha ou almôndegas, preparados com CMS de pescado, por alunos da 
segunda à quarta série do primeiro grau (HIGUCHI; DALLAGNOL, 2012; VITORASSI, 2012; OLIVEIRA-FILHO et al., 2010).

O teor de proteínas próximo a $15 \%$ e os baixos teores de oxidação lipídica e de nitrogênio podem ser relacionados com a análise sensorial, que avaliou a aparência, o odor, o sabor, a textura e a aceitação global do fishburger de surimi de tilápia. As médias para os parâmetros avaliados ficaram próximas de 7,0, em uma escala que variava de um a nove pontos, demonstrando aceitação do produto (Figura 1).

Figura 1. Escores para os atributos de qualidade do fishburger elaborado com surimi de tilápia nilótica (Oreochromis niloticus).

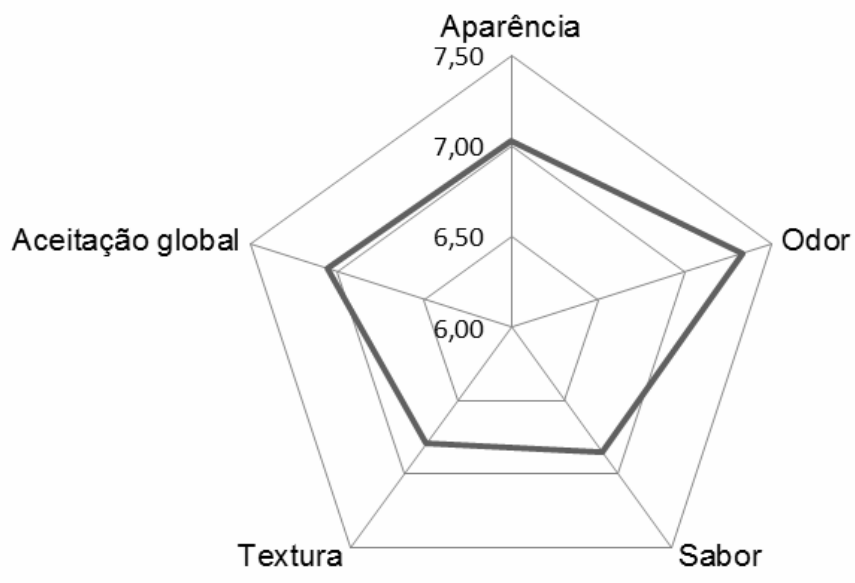

Fonte: Elaboração dos autores.

O odor obteve a maior pontuação média $(7,33 \pm$ $1,34)$, enquanto a textura apresentou a menor nota $(6,79 \pm 1,71)$. A aceitação global obteve nota média de 7,06 $\pm 0,97$ (gostei moderadamente), enquanto o sabor e a aparência receberam notas médias de 6,85 $\pm 1,28$ (gostei) e 7,03 \pm 1,36 (gostei moderadamente) respectivamente (Figura 1).

A pontuação média obtida no fishburger de surimi de tilápia foi superior aos valores descritos para nuggets de CMS lavada de tilápia, que receberam nota média de 6,95 e 6,33 no teste de aceitação global realizado com crianças entre $8 \mathrm{e}$ 15 anos (KIRSCHNIK, 2007). Sebben et al. (2000) avaliaram os mesmos atributos para fishburger de carpa comum (Cyprinus carpio) elaborado com surimi lavado três vezes e obtiveram médias de
5,63 para aparência, 6,75 para odor, 5,05 para gosto e 5,63 para textura (valores transformados de uma escala hedônica que variava de zero a cinco pontos para uma escala de um a nove pontos).

Conclui-se que o surimi pode ser empregado como matéria-prima na elaboração de fishburger, por apresentar elevado teor protéico, estabilidade lipídica e boa aceitação sensorial. O uso da CMS para obtenção de surimi é uma opção para melhor aproveitamento dos coprodutos da filetagem de tilápia nilótica.

\section{Agradecimentos}

À FAPESP pelo apoio financeiro ao projeto. 


\section{Avaliação do Comitê de Ética em Pesquisa Humana}

Para a realização da análise sensorial, o projeto foi submetido e aprovado pelo Comitê de Ética em Pesquisa Humana da Faculdade de Medicina, da Universidade Estadual Paulista, UNESP, Botucatu (OF.520/2006-CEP). Os voluntários assinaram um termo de consentimento, estando cientes e de acordo com a pesquisa, recebendo informações a respeito do projeto.

\section{Referências}

AGÊNCIANACIONAL DE VIGILÂNCIA SANITÁRIA - ANVISA. Resolução - RDC $\mathrm{n}^{0} 12$, de 2 de janeiro de 2001. Disponível em: <http://www.abic.com.br/ arquivos/leg_resolucao12_01_anvisa.pdf $>$. Acesso em: 23 jan. 2013.

ALFARO, A. T.; LANES, G. F. C.; TORRES, L. M.; SOARES, G. J. D.; PRENTICE, C. H. Parâmetros de processamento e aceitabilidade de apresuntado elaborado com surimi de pescada-foguete (Macrodon ancylodon). Alimentos e Nutrição, Araraquara, v. 15, n. 3, p. 259-265, 2004.

BORGHETTI, J. R.; OSTRENSKY, A. Pesca e aquicultura de água doce no Brasil. In: REBOUÇAS, A. C.; BRAGA, B.; TUNDISI, J. G. Águas doces no Brasil: capital ecológico e conservação. São Paulo: Escrituras, 1999. cap. 13, p. 451-466.

BOSCOLO, W. R.; HAYASHI, C.; MEURER, F. Digestibilidade aparente da energia e proteína das farinhas de resíduo da filetagem da tilápia do Nilo (Oreochromis niloticus) e da corvina (Plagioscion squamosissimus) e farinha integral do camarão canela (Macrobrachium amazonicum) para a tilápia do Nilo. Revista Brasileira de Zootecnia, Viçosa, MG, v.33, n. 1, p. 8-13, jan./fev. 2004.

BRITO, L. F. Uso de farinha de sangue na nutrição de frangos de corte. Osasco: Poli-nutri, 2007. Disponível em: $<$ www.polinutri.com.br/conteudo_artigos_ anteriores_agosto_07.htm>. Acesso em: 03 mar. 2013.

CODEX ALIMENTARIUS COMMISSION - FAO/ WHO/UNU. Energy and protein requirements. Report of a joint $\mathrm{FAO} / \mathrm{WHO} / \mathrm{UNU}$ expert consultation. World Health Organization Technical Report Series n. 724. Geneva: FAO, 1985.

Protein quality evaluation. Report of a joint $\overline{\mathrm{FAO} / \mathrm{W}} \mathrm{HO} / \mathrm{UNU}$ expert consultation. Geneva: World Health Organisation (WHO), 1991.
CONTRERAS-GUZMÁN, E. S. Bioquímica de pescados e invertebrados. Santiago: CECTA-USACH, 2002. 309 p.

EYMARD, S.; CARCOUET, E.; ROCHET, M. J.; DUMAY, C.; GENOT, C. Development of lipid oxidation during manufacturing of horse mackerel surimi. Journal of the Science of Food and Agriculture, London, v. 85, n. 10, p. 1750-1756, 2005.

FERREIRA, M. W.; SILVA, V. K.; BRESSAN, M. C.; FARIA, P. B.; VIEIRA, J. O.; ODA, S. H. I. Pescados processados: maior vida-de-prateleira e maior valor agregado. Lavras: UFLA, 2002, 26 p. Disponível em: $<$ http://www.nucleoestudo.ufla.br/naqua/publicacoes/ boletins_tecnicos/Pescados\%20processados.pdf $>$. Acesso em: 01 jul. 2005.

FOLCH, J.; LEES, M.; SLOANE-STANLEY, G. H. A simple method for isolation and purification of total lipids from animal tissue. Journal of Biological Chemistry, Rockville, v. 226, n. 1, p. 497-509, 1957.

GRYSCHEK, S. F. B.; OETTERER, M.; GALLO, C. R. Characterization and frozen storage stability of minced Nile tilapia Oreochromis niloticus and red tilapia Oreochromis spp. Journal of Aquatic Food Product Technology, Binghamton, v. 12, n. 3, p. 57-69, 2003.

HASSAN, F.; MATHEW, S. Physico-chemical, microbiological and sensory characteristics of washed fish mince prepared from some selected species of fish. Journal of Food Science and Technology, Mysore, v. 36, n. 5, p. 459-462, 1999.

HIGUCHI, L.H.; DALLAGNOL, J. M. Desenvolvimento de almondega e quibe de pescado, como alternativa para merenda escolar em Itaipulândia, PR. Revista Higiene Alimentar, Cascavel, v. 26, n. 204/2-5, p. 110-115, jan./ fev. 2012.

KE, P. J.; CERVANTES, E.; ROBLE-MARTINEZ, C. Determination of thiobarbituric acid reactive substances (TBARS) in fish tissue by an improved distillationspectrophotometric method. Journal of the Science and Food Agriculture, Oxford, v. 35, n. 11, p. 1248-1254, 1984.

KIRSCHNIK, P. Avaliação da estabilidade de produtos obtidos de carne mecanicamente separarda de tilápia nilótica (Oreochromis niloticus). 2007. Tese (Doutorado em Aquicultura) - Centro de Aqüicultura. Universidade Estadual Paulista, Jaboticabal.

KIRSCHNIK, P. G.; MACEDO-VIEGAS, E. M. Efeito da lavagem e da adição de aditivos sobre a estabilidade de carne mecanicamente separada de tilápia do Nilo (Oreochromis niloticus) durante a estocagem a $-18^{\circ} \mathrm{C}$. 
Ciência e Tecnologia de Alimentos, Campinas, v. 29, n. 1, p. 200-206, 2009.

LEE, C. M. Surimi process technology. Food Technology, Chicago, v. 40, n. 11, p. 69-80, 1984.

LIMA, S. B. P.; RABELLO, C. B-V.; DUTRA JUNIOR, W. M.; LUDKE, M. C. M. M.; COSTA, F. G. P. Avaliação nutricional da farinha da cabeça de camarão marinho (Litopenaeus Vannamei) para frangos de corte. Revista Caatinga, Mossoró, v. 20, n. 3, p. 35-39, jul./set. 2007.

MARENGONI, N. G.; POZZA, M. S. S.; BRAGA, G. C.; LAZZERI, D. B.; CASTILHA, L. D.; BUENO, G. W. Caracterização microbiológica, sensorial e centesimal de fishburgers de carne de tilápia mecanicamente separada. Revista Brasileira de Saúde e Produção Animal, Salvador, v. 10, n. 1, p. 168-176, 2009.

MELO, H. M. G.; MOREIRA, R. T. P.; DÁLMAS, S.; MACIEL, M. I. S.; BARBOSA, J. M.; MENDES, E. S. Viabilidade da utilização da carne mecanicamente separada (CMS) de tilápia do Nilo na elaboração de um produto tipo "mortadela". ARS Veterinária, Jaboticabal, v. 27, n. 1, p. 22-29, 2011.

MENDES, R. Polpa e surimi de pequenos pelágicos da costa portuguesa. 2001. Dissertação (Mestrado em Investigador Auxiliar) - Instituto de Investigação das Pescas e do Mar, Lisboa.

MENDES, R.; GONÇALVES, A.; NUNES, M. L. Protein and amino acid changes in sardine (Sardina pilchardus) and Horse Mackerel (Trachurus trachurus) minces with washing. In: SIMPÓSIO INTERNACIONAL NOPROT 91, 1., 1991, Faro. Anais... Faro: Instituto de Investigação das Pescas e do Mar, 1991.

MINOZZO, M. G.; VAZ, S. K. Pasta de tilápia Surimi. In: BOSCOLO, W. R.; FEIDEN, A. (Ed.). Industrialização de tilápias. Toledo: GFM Gráfica \& Editora, 2007. cap. 5, p. 83-96.

MIRA, N. V. M.; LANFER-MARQUEZ, U. M. Avaliação da composição centesimal, aminoácidos e mercúrio contaminante de surimi. Ciência e Tecnologia de Alimentos, Campinas, v. 25, n. 4, p. 665-671, out./dez. 2005.

MINISTÉRIO DA PESCA E AQUICULTURA - MPA. Boletim estatístico da pesca e aquicultura: Brasil 2010. Brasília: MPA, 2010a. Disponível em: <http://www.mpa. gov.br/index.php/topicos/300-boletim-estatistico-dapesca-e-aquicultura-2010>. Acesso em: 20 jul. 2013.

Promoção do pescado na alimentação escolar. Brasília: MPA, 2010b. Disponível em: $<$ http://www. mpa.gov.br/index.php/infraestrutura-e-fomentompa/ fomento/incentivo-a-comercializacao/26-infraestrutura- e-fomento/387-pescado-na-alimentacao $>$. Acesso em: 18 out. 2013.

MOORE, S. J. On the determination of cystine as cysteic acid. Journal of Biological Chemistry, Baltimore, v. 238, n. 12, p. 235-237, 1963.

OFFICIAL METHODS OF ANALYSIS - AOAC. Official methods of analysis of the Association of Official Analytical Chemists International, $17^{\text {th }}$ ed. Arlington: AOAC, 2005. 937 p.

OGAWA, M.; MAIA, E. L. Manual de pesca, ciência e tecnologia do pescado. São Paulo: Livraria Vilela, v. 1, 1999. p. 221-249.

OLIVEIRA-FILHO, P. R. C.; NETTO, F. M.; RAMOS, K. K.; TRINDADE, M. A.; MACEDO-VIEGAS, E. M. Elaboration of sausage using minced fish of nile tilapia filleting waste. Brazilian Archives of Biology and Technology, Curitiba, v. 53, n. 6, p. 1383-1391, nov./dec. 2010.

PESSATTI, M. L. Aproveitamento dos subprodutos do pescado. Meta 11. Relatório final de ações prioritárias ao desenvolvimento da pesca e aquicultura no sul do Brasil. Convênio Ministério da Agricultura, Pecuária e Abastecimento (MAPA), Universidade do Vale do Itajaí: MA/SARC, n.003/2000. 2001. $32 \mathrm{p}$.

REBOUÇAS, M. C.; CASTRO, R. J. S.; RODRIGUES, M. C. P.; MESQUITA, M. S. C.; VIEIRA, J. M. M. Caracterização química de carne mecanicamente separada de tilápia-do-Nilo (Oreochromis niloticus) obtida de diferentes sistemas de cultivo. In: ENCONTRO DE INICIAÇÃO À PESQUISA, 14., 2008, Fortaleza. Anais... Fortaleza: Universidade de Fortaleza, 2008.

REBOUÇAS, M. C.; RODRIGUES, M. C. P.; CASTRO, R. J. S.; VIEIRA, J. M. M. Caracterização do concentrado protéico de peixe obtido a partir dos resíduos da filetagem de tilápia do Nilo. Semina: Ciências Agrárias, Londrina, v. 33, n. 2, p. 697-704, 2012.

SARY, C.; FRANCISCO, J. G. P.; DALLABONA, B. R.; MACEDO, R. E. F. de; GANECO, L. N.; KIRSCHNIK, P. G. Influência da lavagem da carne mecanicamente separada de tilápia sobre a composição e aceitação de seus produtos. Revista Acadêmica, Ciências Agrárias e Ambientais, Curitiba, v. 7, n. 4, p. 423-432, out./dez. 2009.

SEBBEN, C. L.; BEIRÃO, L. H.; MEINERT, E. M.; TEIXEIRA, E.; DAMIAN, C. Rendimento e avaliação sensorial de hambúrgueres de carpa (Cyprinus carpio) com diferentes condições de processamento e armazenamento sob congelamento. Boletim CEPPA, Curitiba, v. 18, n. 1, p. 1-12, jan./jun. 2000. 
SIMÕES, M. R.; RIBEIRO, C. F. A.; RIBEIRO, S. C. A.; PARK, K. J.; MURR, F. E. X. Composição físicoquímica, microbiológica e rendimento do filé de tilápia tailandesa (Oreochromis niloticus). Ciência e Tecnologia de Alimentos, Campinas, v. 27, n. 3, p. 608-613, jul./set. 2007.

SPACKMAN, D. H.; STEIN, W. H.; MOORE, S. Automatic recording apparatus for use in chromatography of amino acids. Analytical Chemistry, Washington, v. 30, n. 7, p. 1190-1206, 1958.

STEFANSSON, G.; NIELSEN, H. H.; SKÅRA, T.; SCHUBRING, R.; OEHLENSCHLÄGER, J.; LUTEN, J.; DERRICK, S.; GUDMUNDSDÓTTIR, G. Frozen herring as raw material for spice salting. Journal of The Science and Food Agriculture, Oxford, v. 80, n. 9, p. 1319-1324, 2000.

STONE, H.; SIDEL, J. L. Sensory evaluation practices. 2. ed. San Diego: Academic Press, 1992. 338 p.

SUCASAS, L. F. A. Avaliação do resíduo do processamento de pescado e desenvolvimento de coprodutos visando o incremento da sustentabilidade na cadeia produtiva. 2011. Tese (Doutorado em Ciências) - Universidade de São Paulo, Piracicaba.

SUZUKI, T. Tecnologia de las proteínas de pescado y krill. Zaragoza: Acribia, 1987. 230 p.
TENUTA-FILHO, A.; JESUS, R. S. Aspectos da utilização de carne mecanicamente separada de pescado como matéria prima industrial. Boletim da Sociedade Brasileira de Ciência e Tecnologia de Alimentos, Campinas, v. 37, n. 2, p. 59-64, 2003.

VAZ, S. K. Elaboração e caracterização de linguiça tipo fresco "tipo Toscana" de tilápia (Oreochromis niloticus). 2005. Dissertação (Mestrado em Tecnologia de Alimentos) - Universidade Federal do Paraná, Curitiba.

VIDOTTI, R. M.; GONÇALVES, G. S. Produção e caracterização de silagem, farinha e óleo de tilápia e sua utilização na alimentação animal. São Paulo: Instituto de Pesca, 2006. 20 p.

VITORASSI, D. C. Desenvolvimento de quibe de carne mecanicamente separada de tilápia com adição de linhaça (Linum usitatissimum L.) para inserção na merenda escolar. 2012. Monografia (Trabalho de Conclusão de Curso em Tecnólogo em Alimentos) - Universidade Tecnológica Federal do Paraná, Medianeira.

VYNCKE, W. Direct determination of the TBA value in trichloroacetic acid extract of fish as a measure of oxidative rancidity. Fette-Scifen Anstrichmittel, Berlim, v. 72, n. 12, p. 1084-1087, 1970. 
